\title{
Interorganizational patterns in collaboration - implications for Danish manufacturing industry
}

\author{
M. W. Hansen, C. Møller \\ Department of Production, Aalborg University \\ Fibigerstraede 16, 9220 Aalborg, Denmark \\ Tel: +459635893 or +4596358967 \\ Fax: +4598153030 \\ e-mail:mwh@iprod.auc.dkor charles@iprod.auc.dk
}

\begin{abstract}
In the view of manufacturing some form of interorganizational collaboration is a necessity (Lamming, 93). However, the effective management and understanding of the most effective collaboration is yet to be understood.

This paper presents the findings of a survey Partnership in Danish Industry carried out at the Department of Production, Aalborg, Denmark. The survey findings are empirical data gathered from 1997-1998. The findings of the partnership survey are compared with the findings of three other surveys to develop further assumptions of interorganizational collaboration in Danish Industry.

The paper attempts to sketch out the direction of Danish manufacturers and to identify possible differences of interorganizational collaboration when compared to other region manufacturers (i.e. U. S. and Asia).

The paper describes aspects of the survey research and presents the background of each of the four surveys. Then will discuss results of the survey comparison findings, and provide implications and case study examples to imply how Danish manufacturing industry might direct their efforts to become more collaborative.

Some of the issues examined include process and customer focus supply chain, operational performance measures, supplier evaluation criteria, and outsourcing.
\end{abstract}

Keywords

Interorganizational Collaboration, Network Classification, Survey 


\section{INTRODUCTION}

The position of most manufacturers is within a complex exchange of demands in a process that involves customers on one end and suppliers on the other. This complex exchange process should continually improve to support the interorganizational flow of materials from the raw material side to the customer side of the supply chain.

To handle these complex exchange processes, manufacturing literature (i.e., Lamming, 1993; Goldman, 1995) has touted greater interorganizational collaboration and integration with other specific organizations to develop a greater manufacturing process. With the goal being to drive cost out of the manufacturing process, and to continuously improve the efficiency and flexibility of the manufacturing cycle to meet the needs of the customer.

Therefore, it becomes an imperative issue for every manufacturer that an understanding of the form and nature of collaboration pattern between organizations is understood.

To demonstrate differences in collaboration patterns a number of manufacturing organizations from different regions place their focus on the different areas within interorganizational issues. For example, Asia Pacific and European companies involve the upside of their supply chain, where generally North American companies focus on the downside or final customer (KPMG, 1998).

This paper is not about what focus will improve or impede the progress toward greater collaboration. It's about providing more understanding of the different patterns of collaboration. By asking the question, What are the different approaches taken to collaboration? And, What are the areas of collaboration? The paper will put in context the empirical findings and further use case examples to clarify the collaboration differences.

\section{COLLABORATION IN MANUFACTURING}

There are many elements in the growing global manufacturing of products that lead to more interorganizational collaboration. These elements are stated in (Goldman, 1995). Some of these are the demanded level of customer service; the continuous shrinking of most product life cycle's; the continuous reduction of production time; and the constant change. From the change in these elements have given birth to more complex interorganizational manufacturing processes, where the collaboration between companies involve many more facets of today's organization.

The need in manufacturing is evident that some form of collaboration between a manufacturer and supplier of components or assemblies is essential. Stated in (Bragg, 1998) that as it becomes evident to collaborate, it has an effect on how the organization views its role in the type or form of collaborative interaction. Consequently, from this, companies realize that complex processes that once were held in one organization can be improved through collaboration. Also becoming evident is 
the type of collaboration. In (Møller, 1998) is a network classification model previously presented at the W.G. 5.7 conference (Bitichi, 1998). Defined are three types of collaboration the supply chain, the virtual company and the task force that cover distinctly different relationships and suggest that their processes and emerging structures are different.

In (Bragg, 1998; Greaver, 1999) both state the level of collaboration is progressing from simple process or task to more integrated complex processes of manufacturing of complete components, and also the outsourcing of an entire manufacturing function i.e. assembly.

\section{METHOD}

The aim of this paper is to establish the different patterns of collaboration, and identify the areas of collaborative difference for the further research of collaborative patterns. The "Survey of Partnerships in Danish Industry" (Dreier et al., 1997) bases its questions and findings from Supply Chain Management and Outsourcing theory. The findings of this survey will be compared to three other survey findings based on Global Supply Chain Management and Outsourcing.

\section{A Survey of Partnerships in Danish Industry}

This survey was carried out at the Department of Production at Aalborg University, Denmark. The purpose of the survey was to measure the level of manufacturers understanding of the concept partnership. In total 210 manufacturers with an average of 250 employees or more were selected from Denmark's Statistic and Branch Code CD-ROM database.

The manufacturing segments covered were Textile, Iron and Metal, Machining, Office and EDB Equipment, Tele-Communications and Windmills. Of these, 48 manufacturers or 22.9 per cent answered the questionnaire (Dreier, 1997). The industry segments were measured from questions in four important areas for collaboration, and then applied these measures to a scoring scale. The areas are organization, strategy, management and control, and the exchange and communication of information.

The three following surveys: Global Supply Chain Management Benchmarking Study 1998 (KPMG Management Consulting, 1998); and two surveys under the heading of Outsourcing 1997 and Outsourcing 1998, both Danish text (PA Consulting Group, 1997 and 1998). These surveys are used in conjunction with the Partnership in Danish Industry survey to illustrate the collaboration findings.

\section{Global Supply Chain Management Benchmarking Study 1998}

The purpose of this survey was to understand how closely current supply chain operations around the world reflect concepts of supply chain management. A total of 460 companies from all of the major industry sectors, spanning 24 countries in all the principle regions of the world. Approximately two-thirds of the companies were in the Manufacturing Sector. The remainder were in Distribution (KPMG, 1998). 


\section{Outsourcing 1997 \& Outsourcing 1998}

The purpose of this survey is an annual survey to determine the level of use and understanding of the concept of Outsourcing in the private and public sectors within Denmark. The main conclusion of this survey is based on responses from 195 top managers in 1997 (PA Consulting group, 1997) and 199 top managers in 1998 (PA Consulting group, 1998).

\section{RESULTS OF PARTNERSHIP SURVEY}

The survey results show a pattern of understanding of interorganizational collaboration. Although, the larger companies show greater understanding of collaboration when compared to the smaller companies in the study. Explanation of this can be that the larger companies are exposed to internal collaboration, because of number of departments and employees. Also, the larger companies have shown to have a greater number of supplier's in- and outside of the country.

Results show that $85 \%$ of the respondents are wanting to development toward closer collaboration in the future with suppliers. Of them $90 \%$ want to develop the closer collaboration with certain defined suppliers, and at the same time decrease the number of suppliers. Of these $88 \%$ have made it part of their strategy to reduce the number of suppliers and form closer interorganizational collaboration. From the respondents that favored closer relationships with fewer suppliers shown a greater average score of understanding collaboration. This compared to the respondents who favored closer collaboration with all suppliers.

The segment of the manufacturing of office and EDB equipment and Telecommunication equipment have scored the highest in rating of understanding of greater collaboration. Reasons for this can be that the products are more complex. For example, a major TV and Audio Equipment in Denmark has developed product design collaborations for CD-Players and metal components. Further illustrates that there is a tendency that companies with complex products and processes understand the use of collaboration.

Another results of all the respondents illustrate interorganizational collaboration of $33 \%$ in design, $22 \%$ in development and $30 \%$ in assembly. Of all respondents $35 \%$ of design, $28 \%$ of development and $30 \%$ assembly indicate that there will be a future increase in collaboration of these areas. This can further indicate that companies see an economic gain with tighter collaboration of complex processes. It also illustrates a focus upstream in the supply chain in Danish Industry. Although, in this study it can not be concluded that this illustrates a high or low number that actually collaborate with suppliers to develop or take part in developing products or processes. It could also be said that companies do not use closer collaboration in areas where it is most suitable.

The six most important factors in identifying a supplier are presented in order of importance, they are delivery dependability, quality of product service, delivery of proper quantity, supplier's performance, and price. This can be seen as an openness to work with the suppliers and not only watch after price. In conclusion, the belief 
in general toward collaboration in Danish Industry is positive and is comparable to most American and Japanese theory of collaboration in manufacturing literature.

\section{DISCUSSION}

In this section will be a discussion of the findings of the Partnership Survey in Danish Industry in relation to the other three surveys discussed prior in this paper. Below in Table 1 illustrates four regions of discussion and four characteristics. The measure of the characteristics placed in Table 1 is to provide an illustration of differences between regions. They are not exact measures, but are noted as differences in the survey findings. Plus symbols are used to note a greater difference between the same measure given to two different regions.

Table 1 Illustrates regions of manufacturing and characteristics

Manufacturing Regions

\begin{tabular}{lcccc} 
& Denmark & Europe & Asia & N. America \\
\hline $\begin{array}{l}\text { Supply Chain Focus } \\
\begin{array}{l}\text { Performance } \\
\text { measures known }\end{array}\end{array}$ & Upside + & Upside & Downside & Downside + \\
$\begin{array}{l}\text { Collaboration of } \\
\text { Complex process }\end{array}$ & Increase & Well known & Known & Known \\
$\begin{array}{l}\text { Ability to } \\
\text { collaborate }\end{array}$ & Middle & High & Increase & Increase \\
\hline
\end{tabular}

The supply chain focus of the Danish region is on the upside of the supply chain. In (Dreier, 1997) the Partnership Survey the findings show that manufacturers are more interested in collaborating on processes of product flow through the supply chain as well as a low percent of manufactures working with suppliers in development, design and assembly of products. In the (KPMG, 98) survey it notes that Asia Pacific and European companies involved their suppliers significantly more than North American companies. However, The findings indicate this to be true from supportive outsourcing collaboration to complex type collaboration processes. In the (PA Consulting 97 and 98) have shown Danish Industry in a steady growth of collaboration with suppliers on complex processes. In the (KPMG, 98) survey all regions indicated that an increase of collaboration on complex process will be noticed. 
Performance indicators noted in the (KPMS, 98) survey indicated that European manufacturers feel they have adequate performance indicators and evaluated themselves much higher than the other regions. In manufacturing performance $61 \%$ of European manufacturers to the next highest $56 \%$ of North American manufacturers. Although, in the (PA Consulting, 98 and KPMS, 1998) surveys is that many small European companies are lacking internal capability, control, resources and investment for developing collaborations.

In Danish Industry $98 \%$ of Danish companies can be classified as small with less than 250 employees. With information technology improving and becoming easier to implement, the noted deficiencies should become less of a barrier to collaborative development. Another indicator is inventory, where European inventory is lowest at $13 \%$ with North Americans at $14 \%$. (KPMS, 98) note it reflects the expected benefits of technology and greater effectiveness of supply chain management. This can be an indicator of the noted increase of collaborative activity of Danish Industry in the last two years, noted in (PA Consulting, 97 and 98) surveys.

\section{CONCLUSIONS}

In the following is discussed the implications and tendencies from the results that have been presented in this paper. First, a summation of conclusions and then identified are conclusions that will be drawn out for future research.

The first discussion is that the respondents of the Partnership of Danish Industry survey generally have an average understanding of collaboration. Furthermore, it can be concluded that there are tendencies that complex products and processes demand collaboration. In addition, Danish Industry is recognizing that there is an economic gain with more integrated collaboration. This is indicated by the increase in the complex collaboration in areas i.e., design, development and assembly within Danish Industry

Although, noted in the (KPMG, 98) survey that Danish manufacturers still use their suppliers to little to develop or take part in developing products or processes through collaboration. This also means that manufacturers do not use closer collaboration in areas where it is most suitable.

Moreover, it generates questions of how and where should an organization collaborate to develop its supply chain? These answers affect the effectiveness and performance of the supply chain. It was further discussed that manufacturers in Danish Industry will need to understand the multiple forms of interaction. This is because of the greater variety of customers served by manufacturers. This understanding will have to come from further research of the phenomena. The research should study the design of the configuration and the adaptability of the different interaction forms. Because these forms are not applicable to all organizations a further understanding of the contingencies for reconfiguration and use is needed. 
In this paper we have presented findings to provide an aspect of collaboration in Danish Industry and other manufacturing regions.

\section{REFERENCES}

Bitichi, U.S \& Carrie, A.S. (1998), Strategic Management of the Manufacturing Value Chain, Kluwer Academic Publishers.

Bragg, Steven M. (1998), Outsourcing - A Guide to...Selecting the Correct Business Unit...Negotiatig the Contract...Maintaining Control of the Process, John Wiley \& Sons, Canada.

Dreier, J., Gislason, K.J., Hansen, M.W., Havgaard, D.L., Jensen, B.Q., and Kaspersen H.H. (1997), Partnerskab - tillid frem for frygt (A Survey of Partnerships in Dansih Industry), Aalborg University, Denmark.

Goldman, S.L., Nagel, R.N., and Preiss, K. (1995), Agile Competitors and Virtual Organizations - Strategies for Enriching the Customer, Van Nostrand Reinhold.

Greaver II, Maurice F. (1999), Strategic Outsourcing - A Structured Approach to Outsourcing Decisions and Initiatives, American Management Association.

KPMG Management Consulting (1998), Global Supply Chain Management Benchmarking Study, KPMG Management Consulting, USA.

Lamming, Richard (1993), Beyond Partnerships - Strategies for Innovation and Lean Supply, Prentice Hall.

Møller, C., Riis, J.O., and Hansen M.W. (1998), Interorganizational network classification - A framework for studying industrial networks, in proceedings of IFIP WG 5.7 1998 Working Conference, Troon, Scotland, UK.

PA Consulting Group (1997), Outsourcing 1997: Creating Business Advantage, PA Consulting Group, Denmark.

PA Consulting Group (1998), Outsourcing 1998: Creating Business Advantage, PA Consulting Group, Denmark.

Preiss, K., Goldman, S.L., Nagel, R.N. (1996), Cooperate to Compete - Building Agile Business Relationships", Van Nostrand Reinhold.

\section{BIOGRAPHY}

Charles Møller is Assistant Professor at the Department of Production, Aalborg University. Charles Møller gained his M.Sc. in Electrical Engineering from the Technical University of Denmark, and a Ph.D. from Aalborg University in Denmark. The thesis was entitled: Logistics Concept Development - Towards a Theory for Designing Effective Systems. Previously he has been employed in IBM, Brüel \& Kjær, and in Interconsult Management. His primary research areas at the Department of Production are logistics, production management, simulation and IT. 
Mark Hansen is Ph.D. student at the Department of Production, Aalborg University. Mark Hansen gained his B.Sc. Degree at Embry Riddle Aeronauticle University, USA and M.Sc. at the Department of Production, Aalborg, Denmark. His interests are Integrated Logistics and Agile Manufacturing. 